\title{
Learning through processing: Towards an integrated approach to early word learning
}

\author{
Stephan C. Meylan ${ }^{1,2}$ and Elika Bergelson ${ }^{2}$ \\ ${ }^{1}$ Department of Brain and Cognitive Sciences, MIT (smeylan@mit.edu) \\ ${ }^{2}$ Department of Psychology and Neuroscience, Duke University
}

May 6, 2021

\begin{abstract}
Children's linguistic knowledge and the learning mechanisms by which they acquire it grow substantially in infancy and toddlerhood. And yet, theories of word learning largely fail to incorporate these shifts. Moreover, researchers' often-siloed focus on either familiar word recognition or novel word learning limits the critical consideration of how these two relate. As a step towards a mechanistic theory of language acquisition, we first present a framework of "learning through processing," and relate it to the prevailing methods used to assess children's early knowledge of words. Incorporating recent empirical work, we posit a specific, testable timeline of qualitative changes in the learning process in this interval. Finally, we conclude with several challenges and avenues for building a comprehensive theory of early word learning: better characterization of the input, reconciling results across approaches, and treating lexical knowledge in the nascent grammar with sufficient sophistication to ensure generalizability across languages and development.
\end{abstract}

\section{Introduction}

The English word "infant" derives from the Latin word "infans," meaning "unable to speak." However, even infants know plenty about language by the time they begin to understand common words around 6-9 months (e.g., Bergelson \& Swingley, 2012; Tincoff \& Jusczyk, 1999; Parise \& Csibra, 2012). Infants and toddlers connect the language they experience with the world around them before they have understood others' intentions or fully deduced the complex system of sounds and grammar of their language, and while their memory and attention skills are still developing (Bates, 1979; Carpenter et al., 1998; Diamond, 1985; Fisher \& Gleitman, 2002; Polka \& Werker, 1994). Given young children's changing knowledge and abilities, a mechanistic theory of language acquisition should consider how infants' and toddlers' representations and inferences shift with age. We examine these considerations for the particular case of early word learning. 
In Section 2, we present a framework that relates language learning and processing through a growing store of linguistic knowledge. Here and throughout the article, we focus on early word comprehension in particular, though much of what we say readily extends to other levels of linguistic representation, and could be expanded to early production. We propose that a child's ability to process linguistic inputs changes as they apply available learning mechanisms to a growing history of experience with language, and as the inventory of learning mechanisms itself changes over the early lifespan. We then summarize and link common methods for evaluating linguistic knowledge (familiar word processing experiments, novel word learning experiments, caregiver-reported vocabulary assessments, and naturalistic corpora) to this long timeline of iterated processing. This framework makes it possible to explicitly separate real-time processing, updates to linguistic knowledge as language input accrues, and updates to processing itself as part of linguistic maturation. Further, it provides a way to relate computational modeling proposals (see Computational Models Sidebar) with experimental and observational approaches more broadly.

In Section 3, we propose a specific, empirically-testable timeline of major shifts in word learning before age 2 . These stages include early brute-force associative learning focusing on concrete nouns; a comprehension boost across word classes that appears aligned with social insights, cognitive improvements and metalinguistic awareness; and a broader process of using utterance contexts (e.g., linking semantics with syntactic role) to rapidly build and extend word meanings.

Our perspective highlights three challenges for developing a full-fledged theory of early word learning, which we take up in Section 4. First, while children's linguistic knowledge depends critically on the history of utterances and contexts that they have observed, relatively few longitudinal corpora have been collected, and these have typically captured only small slices of the input (Tomasello \& Stahl, 2004; Roy et al., 2015). Moreover, recordings of children's naturalistic language experiences and experiments measuring word knowledge are usually collected from non-overlapping groups of children (though see Bergelson \& Aslin, 2017; Weisleder \& Fernald, 2013). Second, novel word learning and familiar word processing studies yield somewhat divergent results, prompting questions about whether these methods tap different sorts of language knowledge. Third, the question of what early words are - and, relatedly, what the problem of learning truly entails - requires careful consideration. To meet these challenges, we advocate for 1) longitudinal study designs which tie all four classes of empirical methods together with computational modeling at the level of individual children 2) expanding the set of words under consideration for in-lab processing studies, while carefully considering variability in both forms and meanings.

\subsection{Computational Models (sidebar)}

Formal and computational models are vital for building and testing mechanistic models of language learning and processing (Dupoux, 2018; Pinker, 1979). The first step in such model-building is often creating an ideal observer (or "rational") model Chater et al., 1998 that characterizes the learning problem and an optimal inferential approach. This puts it into a common language across psychology, linguistics, computer science, and robotics. Bayesian approaches are particularly helpful for placing diverse propos- 
als in a common space relating hypotheses to data and inductive biases via probabilities (Griffiths et al., 2010). The second step is then revising these models to be increasingly representative of the learning or processing challenge, by adding more realistic inputs (e.g., raw video rather than symbolic representations of context), resource constraints (reflecting attention and memory limits), scales of input and output (approximating the history of children's experience), and interactions with other learning processes. Computational models are becoming increasingly important in bridging the gap between verbal theories and empirical data, by requiring explicit, testable articulation of the implementation and outcomes of complex processes, like word learning (Hill et al., 2020).

\section{How Does Lexical Processing Relate to Word Learn- ing?}

\subsection{A Framework for Learning Through Processing}

Our framework makes three general commitments. First, young children have a revisable store of linguistic knowledge. This knowledge ranges from familiarity with the phonology of their first language developed in utero (e.g., Moon et al., 2013) to fully mature representations years later. Second, learners use the current state of this store of linguistic knowledge to process incoming utterances. Iterative processing provides the experience necessary for learning, while iterative learning leads to better processing. In this sense, all evaluations of word knowledge are actually reflections of children's abilities to process language. Finally, contextual factors (e.g., scene, discourse, and larger linguistic context) are vital inputs to language processing, and become increasingly relevant as cognitive and social capacities improve (see Section 3).

We conceive of language processing as meaning inference (Magnuson, 2017). In line with proposals of noisy-channel processing (Shannon, 1948) in adult psycholinguistics (Gibson et al., 2013; Levy, 2008), we assume that processing requires evaluating hypotheses about intended meanings in light of perceptual signals and probabilistic expectations. This means that children take into account what they think people are likely to mean, and how they are likely to encode what they mean (Gibson et al., 2013; Meylan, Nair, \& Griffiths, 2021). While more mature language users can explicitly consider possible meanings with respect to speakers, and a speaker's model of the listener (e.g., rational speech acts, Bohn \& Frank, 2019) young children too still build rich expectations.

In our framework (Fig.1), a child's language knowledge takes the form of a probabilistic decoder that takes in a linguistic signal (i.e., spoken or signed utterance) and a non-linguistic context, and outputs a probability distribution over possible meanings, which informs their behavior. Setting aside the thorny philosophical question of what meaning is, we treat it here as a function of the received linguistic signal, the context, and a child's knowledge of both language and the broader world. Critically, the decoder plays a dual role - it is both a processing mechanism, i.e., a probabilistic means of translating from utterances of language input to meaning in real time, and the output 


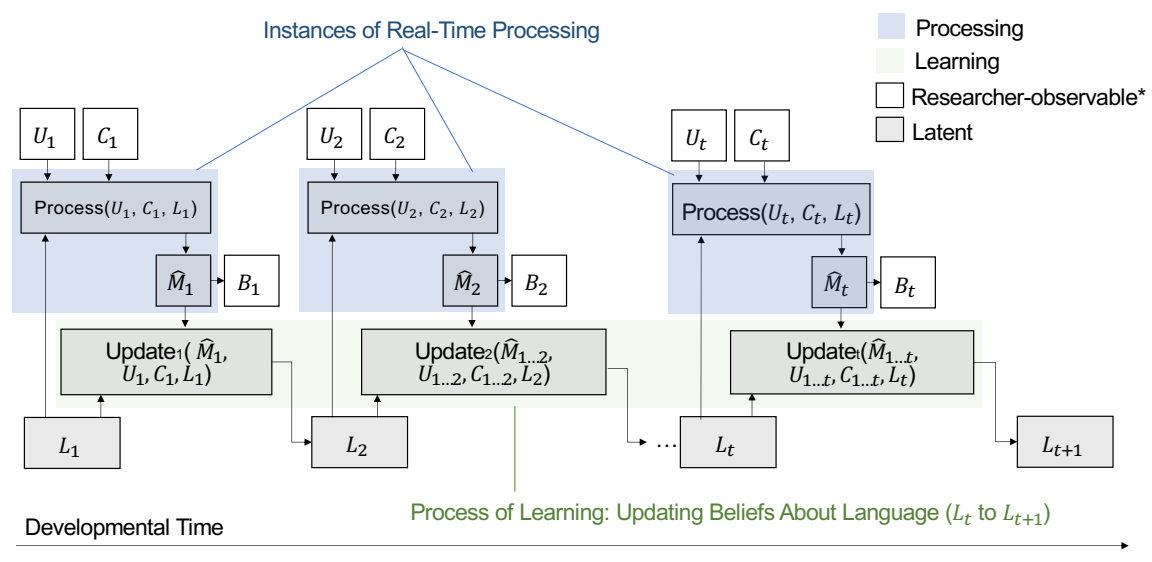

Figure 1: A framework depicting the relationship between input (utterance $U$ and context $C$ ), language knowledge $(L)$, best guess of meaning $(\hat{M})$, and behavior informed by meaning $(B)$ as processing and learning proceed over developmental time. Function arguments indicate dependencies in the causal graph (i.e., what inputs are used in processing or updating). *Utterances, contexts, and behaviors are potentially observable by the researcher, though in practice only snapshots of each are recorded with existing methods (see Fig. 2). Processing and updating inferences are not directly observable. 
of learning: an updateable store of beliefs about language. ${ }^{1}$ That is, the child will (1) as a listener, infer the most likely meaning in a given communicative context (using the current parameter values of the decoder, i.e., the current state of their linguistic knowledge) and (2) as a learner, if needed and possible, update the decoder to parameter settings that would perform best in the learner's estimation. For example, a child might revise a word-to-referent mapping for a concrete noun in the earliest stages of lexical acquisition, and utterance-to-world mappings in later phases (Gleitman, 1990; Gutman et al., 2015).

More formally, in each instance of language processing (blue squares in Fig. 1), the child observes an utterance $U_{t}$ and context $C_{t}$ and decodes them using the language knowledge at that timepoint, $L_{t}$, to produce a probability distribution over potential meanings, $M_{t}$. The highest probability hypothesis is denoted $\hat{M}_{t}$, and reflects the best guess of utterance meaning given the context. This guess informs the child's behavior $B_{t}$. We propose that this computation of a probability distribution over meanings in a specific context is processing.

Having processed the input, the child learner then updates the parameters of the decoder following some objective function (green square in Fig. 1). ${ }^{2}$ Under our proposal, this update process is learning. The child learner then uses the updated decoder to process the next input. Under a rational model of learning, a child could use the complete history of past utterances and contexts, as well as available feedback to evaluate and select a new decoder $L_{t+1}$, though young children clearly have limitations with respect to this idealization. ${ }^{3}$

In our formulation, "language knowledge" is broad. In the mature processor, it encompasses the phoneme and morpheme inventory, phonotactics, hypotheses about how words map to referents or categories, argument structure expectations (e.g., will this verb take an indirect object?), mappings between syntax and semantics (e.g., what would it mean to be the indirect object of "throw"?), pragmatic maxims (e.g., Grice, 1975), inter alia. In principle, all such knowledge could be used to decode utterances and contexts, i.e., to produce expectations regarding utterance meanings. Here we focus particularly on language knowledge regarding words: their forms, meanings, and relationship to each other.

We are certainly not the first to point out the continuum on which lexical processing and word learning exist (McMurray et al., 2012; Swingley, 2010; Carey \& Bartlett, 1978; Katz et al., 1974; Bates \& Goodman, 1997). In particular, this proposal shares with McMurray et al. (2012) the idea that children may exhibit strong performance in short-term inferential processes, and that knowledge gained in such episodes may contribute to longer term learning. However, our view diverges from McMurray et al's claim that short-term processing relies heavily on heuristics and context while long-

\footnotetext{
${ }^{1}$ We use beliefs in the Bayesian sense, i.e., probabilistic expectations, and do not imply anything about conscious consideration of such beliefs.

${ }^{2}$ We leave the specification of the objective function to future work, but are sympathetic to a reinforcement learning approach (e.g., Hill et al., 2020) where learners pick decoder parameters that they expect will maximize future reward, i.e., its utility.

${ }^{3}$ This proposal is phrased at Marr's "computational" level of analysis (Marr, 1982), which ignores processing or storage constraints, and instead envisions an "ideal" learner/processor. Our framework is agnostic vis-a-vis constraints at the algorithmic level, of which there are many. We find proposals on resource rationality particularly useful for considering these constraints (Lieder \& Griffiths, 2019).
} 
term learning progresses by associative mechanisms. We instead affirm a "big tent" approach in which many mechanisms of learning and processing co-exist; the exact mixture available varies across children (Kidd \& Donnelly, 2020), and across developmental time (Section 3).

As presented here, our framework leaves many open questions. For example, how can a child revise linguistic knowledge with respect to previous experience with language? How long is the history of utterances, contexts, and meanings that the child can use to update language beliefs? How does this account for changes over time in representational richness? When are updates to linguistic beliefs incremental vs. paradigmatic? And of course, how does knowledge at various levels of linguistic representation interact? A notable benefit to our formulation is that existing theoretical and computational accounts that speak to these questions fit into this overarching framework. For example, cross-situational word learning (Smith \& Yu, 2008) and proposebut-verify (Trueswell et al., 2013) make contrasting assertions about the update process with respect to word-to-referent mapping, but are both in principle compatible with the intrinsically-linked notions of learning and processing we propose. Our hope is that creating an encompassing framework to express existing theories in the same terms will hasten progress in adjudicating among them.

\subsection{Empirical Methods}

We next consider how common empirical approaches in the study of word learning relate to this "learning through processing" framework.

\subsubsection{Familiar Word Knowledge}

Tests of familiar word knowledge (Fig. 2, C) aim to evaluate whether young children understand common words. In terms of our framework, such tests evaluate children's knowledge by examining a small number of instances of processing (i.e., test trials) in light of an assumed history of previous language processing (i.e., home language experience) and the concomitant updates to language knowledge this entails (i.e., learning). Because the child's estimate of word meaning cannot be directly accessed, researchers use proxies: behavioral observables including what a child looks at, points to, or selects in response to an utterance, or measures of unexpectedness such as electrical signals in the brain.

The most common method for testing word comprehension in infancy involves tracking looking behavior, particularly measures of looking-time in response to linguistic input (variably called "looking-while-listening," "language-guided-looking," or the "intermodal preferential looking paradigm"; Fernald et al., 1998; Swingley, 2009; Golinkoff et al., 2013; cf. Visual World Paradigm in adults, e.g., Salverda \& Tanenhaus, 2017). In looking-time experiments, researchers show infants images or scenes set up with some sort of contrast (e.g., eating vs. drinking; foot vs. banana, new toy \#1 vs. familiar toy \#2), say an utterance (e.g., "Look, she's eating!"; "Where's the banana?"; "Do you see the block?"), and measure where infants look and for how long (Fernald et al., 1998). This approach is predicated on the notion that looking at what's 


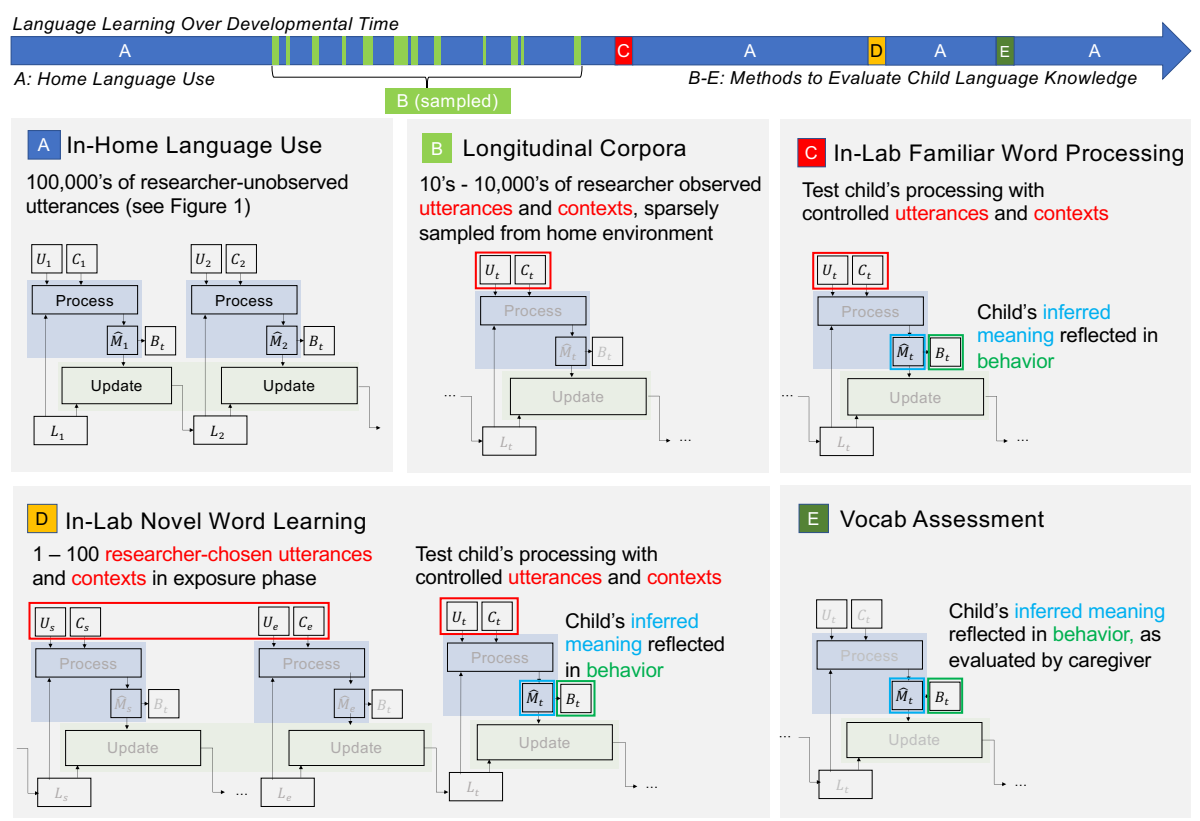

Figure 2: Learning-through-processing in the home (A) related to four common methods of early linguistic knowledge assessment (B-E).(B shows longitudinal corpora as an example of the more general method of home recordings). The top arrow indicates that each of these assessment methods represents a small proportion of a child's history of processing and learning. 
being talked about is an automatic process, given the requisite word knowledge: listeners who know the word "dog" will spontaneously search for one in just a few hundred milliseconds' time upon hearing "Look at the dog!" (Fernald et al., 2006; Salverda \& Tanenhaus, 2017).

A second method for probing word comprehension is to measure correlates of unexpectedness, typically with electroencephalography. In such experiments, children see and/or hear congruent word-pairs (like "shoe-boot"), or word-object pairs (e.g., a picture of a ball and the word "ball" spoken aloud), or incongruent pairs (e.g., a picture of a ball and the word "shoe"). Brain responses like the N400 are then compared for the congruent vs. incongruent pairings (e.g., Forgács et al., 2019; Parise \& Csibra, 2012). A benefit of both of these types of methods is that they directly probe infants' knowledge but require little overt behavioral response, making them suitable for young infants.

A third tack involves prompting a child to select (i.e., point to) a picture in response to a linguistic stimulus, or produce a word in response to a picture, such as a word in the CCT (Friend et al., 2012) or in the PPVT, Picture Naming Task (Dunn et al., 1965). These approaches often require more action planning in the behavioral response than eye movement, and are thus generally used for children older than 18 months.

\subsubsection{Novel Word Learning}

The methods for experimentally measuring children's receptive knowledge of novel words are essentially the same as those outlined for familiar word comprehension. The major distinction is that children have no prior history with the specific word in question (Fig. 2, D). Processing here reflects updates to language knowledge that occur during an exposure or training phase. But as with familiar word comprehension, both processing and learning rely on the child's broader language knowledge-for example, while the word(s) being taught may be novel, their constituent phonemes or syntactic roles within an utterance are not.

New items presented in the exposure phase of novel word learning experiments are typically unusual objects like dog toys (Horst, 2016) or novel actions. The exposure phase in such experiments varies from fully passive exposure to items and words/sentences (Smith \& Yu, 2008), to explicit teaching (Woodward et al., 1994; Oviatt, 1980), to situations where infants are supposed to infer the label of an unseen objects (Tomasello, 2005; Baldwin, 1993), to learning trials with selection in the context of known referents (Horst \& Samuelson, 2008). Participants are exposed to the new items' labels a few dozen times, with test trials (eyetracking- or selection-based) directly following exposure or shortly thereafter.

A major benefit of using novel word learning methods to study lexical acquisition lies in their ability to manipulate learners' access to syntactic and semantic information for the new words (Syrett et al., 2014; Arunachalam et al., 2013; Waxman et al., 2009; Shi, 2014; Zangl \& Fernald, 2007). In particular, work on syntactic bootstrapping has highlighted the utility of considering how entire utterances link up to the oft-ambiguous world, confirming the importance of syntax in helping young children forge such links (Gleitman, 1990; Omaki \& Lidz, 2015; L. Naigles, 1990; Fisher \& Gleitman, 2002; Fisher et al., 2020; L. R. Naigles, 2021). 


\subsubsection{Vocabulary Assessment}

Caregiver reports of children's vocabulary knowledge (e.g., Macarthur Bates Communicative Development Inventory, Fenson et al., 1994) provide a holistic proxy for how many and what kinds of words children can effectively process in the home environment by asking caretakers to report what they believe their child understands (Fig. 2, E). Indeed, previous research finds correlations between in-lab eyetracking with familiar words and caregiver-reported vocabulary size (Fernald et al., 2013). As with the experimental methods above, caregiver reports are not exhaustive, but are constructed to specifically capture a reasonable sample of children's word knowledge at a specific age.

\subsubsection{Corpora From The Home Environment}

A fourth broad method of investigation is to sample children's life and language input and output: i.e., record their everyday experiences (Figure 2, B; VanDam et al., 2016; Brown, 1973; MacWhinney, 2000). Historically, children's productions in such corpora have been taken as evidence of the state of their linguistic knowledge. More recently, caregiver's behavior (linguistic or otherwise) in these corpora have also been used as inputs to both descriptive and corpus-based analyses (Casillas et al., 2020b,a; Bergelson, 2020; Bergelson et al., 2018) and computationally-instantiated learning models that test what sorts of representations and behaviors can be learned by different learning procedures (Regier \& Gahl, 2004; Frank, Goodman, \& Tenenbaum, 2009; Goldwater et al., 2009; Perfors et al., 2011). In terms of our framework, longitudinal corpora supply samples of the history of utterances $U$ and contexts $C$ that we expect to inform linguistic knowledge at a given point in development. While not our focus here, children's own language productions too reflect this knowledge.

\section{How Does Word Leaning and Processing Change Over Time?}

Age is a multi-faceted correlate of learning. Older infants not only possess more mature cognitive and social skills than younger ones, they have also experienced and learned more language; these processes interact (Snedeker et al., 2007; Fernald et al., 2006). Though some accounts hold that exposure to "effective" learning instances explains word learning without appealing to age or maturation (e.g., Mollica \& Piantadosi, 2017), the broad consensus is that older infants are better word learners than younger ones (Bates, 1979; Carpenter et al., 1998; Fernald et al., 2006; Bergelson, 2020). In terms of our framework, the Update function (Figure 1) that children use to transition between hypotheses about the language is not the same for a 8 vs. 14 vs. 20 month old. But how exactly do learning and processing change over developmental time?

Below we provide a specific, falsifiable timeline of representational change during early word learning. This account provides a useful reference point for subsequent empirical work to correct and refine. This is not the first proposal of its type (e.g., L. Bloom, 1993; Hollich et al., 2000; P. Bloom, 2002; Tomasello, 2005; Bates, 
1979). However, growing evidence of early word knowledge (Bergelson \& Swingley, 2012; Campbell, 2018; Bergelson \& Aslin, 2017; Bergelson \& Swingley, 2015; Tincoff \& Jusczyk, 1999, 2012; Kartushina \& Mayor, 2019; Parise \& Csibra, 2012) necessitates a reconsideration of prior proposals.

Research in the 1980's and 1990's on the mechanisms underlying word learning highlighted several types of mechanisms: associative or cue-based (Smith, 2000; Plunkett, 1997; Bates \& MacWhinney, 1989); socio-pragmatic (Carpenter et al., 1998; Tomasello, 2005; Baldwin, 1993); and constraint-based, with both linguistic and conceptual flavors (Clark \& Hecht, 1983; Markman, 1990; Gleitman, 1990). The bulk of empirical evidence pointed to the second half of year two as the age when such mechanisms became available. Subsequent theories have integrated some of these factors, and clarified the role of development (e.g., Hollich et al., 2000; L. R. Naigles, 2021; Tomasello, 2005).

However, research in the 2010's has produced converging evidence that infants begin to understand common nouns at 6 to 9 months across several languages, using both eyetracking and EEG (e.g., Bergelson \& Swingley, 2012; Kartushina \& Mayor, 2019; Parise \& Csibra, 2012). These studies find modest but consistent evidence of word comprehension across infants and items, suggesting that theories need to address how word-learning can transpire in infants who lack the previously-proposed abilities.

We suggest that early word learning is well characterized as a series of at least three successive phases. The initial phase consists of brute-force associations that initiate the lexicon. The next phase is the comprehension boost, wherein infants' receptive word knowledge improves rapidly (Bergelson, 2020). The third phase includes symbiotic syntheses across associative, socio-pragmatic, and conceptual/linguistic constraintbased contributors to learning (e.g., Hollich et al., 2001; Tomasello, 2005). Each phase can be characterized as changes to the Update function in the "learning through processing" framework (Figure 3).

Delineating these phases helps underscore that not all proposed mechanisms of word learning are available to young word learners. For instance, to our knowledge there is no evidence for cross-situational word learning before 12-14 mo. (Smith \& Yu, 2008), and evidence of immature mutual exclusivity before 17 mo. (Halberda, 2003; Markman, 1990). Given word comprehension in younger infants, word learning must be possible without those abilities. In contrast, there are clear qualitative improvements in word learning across year two relative to this initial phase, suggesting additional learning mechanisms become available.

\subsection{Linguistic Data Crunching \& Brute Force Early Associations ( $<10$ mo.)}

The earliest words in the receptive lexicon, based on current empirical data, tend to be nouns that pick out individuals, foods, body parts, and common objects, for example "mommy", "banana", "foot", "ball" (Bergelson \& Swingley, 2012; Campbell, 2018; Bergelson \& Aslin, 2017; Bergelson \& Swingley, 2015; Tincoff \& Jusczyk, 1999, 2012; Kartushina \& Mayor, 2019; Parise \& Csibra, 2012). Words from other lexical classes (e.g., "uh-oh", "eat") follow a few months thereafter (Bergelson \& Swingley, 2013a; 


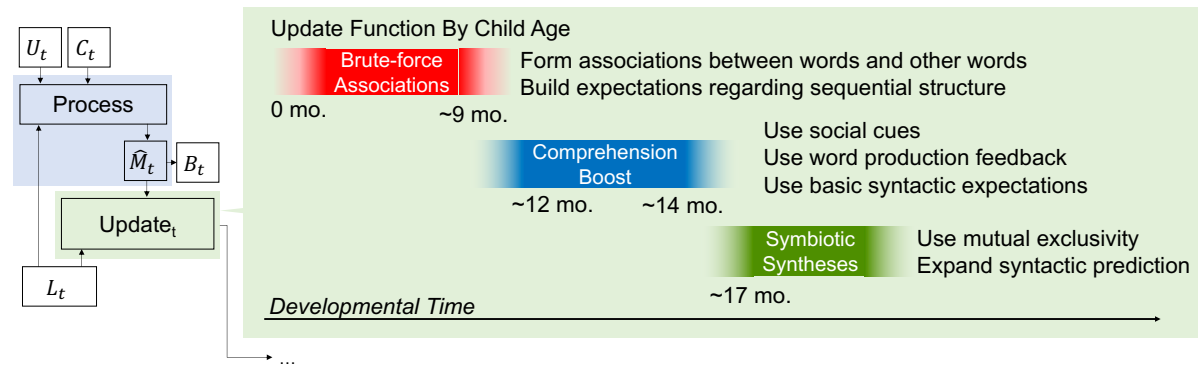

Figure 3: Changes in word learning between 0 and 2 years, presented in terms of the framework introduced in Section 1.

Benedict, 1979). This pattern is cross-linguistically robust according to parental vocabulary assessments (Frank et al., 2021). These early words are notable for at least two reasons. First, they are highly frequent in young infants' input. For example, in a set of daylong audio-recordings taken at 6 and 7 months, infants heard the top 5 concrete nouns $>750$ x over $\sim 20$ waking hours (Bergelson et al., 2018). Second, while early nouns' referents are not all well-delineated and free-standing objects (e.g., "milk"), they do look alike across instances (e.g., most hands look similar). This high input frequency and perceptual consistency are likely critical to these nouns' early learnability. ${ }^{4}$

If mutual exclusivity and intention-reading are not available in year one, what kinds of skills might be harnessed for word-learning in early infancy? Young infants have an increasing interest in faces (Frank, Vul, \& Johnson, 2009), form expectations about goals (Woodward et al., 2009), exhibit multi-modal categorization skills (e.g., Kadlaskar et al., 2020), and isolate word forms (Johnson, 2016). On the other hand, their phoneme inventories and language-specific segmentation strategies are not yet adultlike (Swingley, 2009), and their early memory, attention, and social prowess remain highly rudimentary (e.g., Bates, 1979; Diamond, 1985), making heavy reliance on these abilities for long-term word learning unlikely.

Taken together, the properties of these early-learned words, combined with the relatively limited socio-cognitive skills available over the first half year of life, suggest that brute force associative learning may usher these earliest items into the lexicon. That is, experiencing sentences and situations containing common nouns dozens of times a day every day likely forms the backbone of an interactive process that lets young infants forge initial links between words and meanings. These accretions become the words infants first understand.

We do not suggest that infants' earliest words are akin to the highly-trained, contextuallycircumscribed, interlocutor-specific abilities that e.g., border collies exhibit (Pilley, 2013; Frank, 2016). Rather, this initial phase of human word learning occurs spontaneously, and the words that are first codified are readily generalized to new tokens and decontextualized contexts (e.g., looking-while-listening experiments). But even putting aside the nature of early word representations, we stress that the words and con-

\footnotetext{
${ }^{4}$ Whether children have an adult-like noun category remains an active area of debate (Yang, 2013; Meylan et al., 2017).
} 
cepts infants first link in their receptive lexicons are the result of an intrinsically-driven but slow, hardscrabble process (cf McMurray et al., 2012; Swingley, 2010). Critically, this contrasts with the relative ease with which later lexical entries (which make use of advancing skills) are both initially added, and eventually, readily retained.

\subsection{Comprehension Boost: Cognitive, Social, \& Metalinguistic in- sights ( 12-14 mo.)}

What was once taken as the onset of word learning around 12 months (Tomasello, 2005; P. Bloom, 2002) is perhaps better characterized as a qualitative improvement in word comprehension. Indeed, as social, cognitive, and linguistic skills accrue and word production begins, there is a non-linear improvement in how well infants understand common words, signaling the onset of robust word comprehension (Bergelson, 2020). This boost is noteworthy in part because it doesn't simply reflect changing language input: Language input remains fairly constant over infancy across measures like word counts and utterance types, while comprehension, particularly as measured by looking-while-listening tasks, improves markedly (Bergelson, 2020; Bergelson et al., 2018). This boost is consistent with a learner whose processing of language input goes through iterative error-reduction based improvement, while the learning "substrate" (i.e., language input) stays consistent along many dimensions.

Since we have written about the potential causes and consequences of this boost elsewhere (Bergelson, 2020), we note here simply that there remains important work to be done to understand which aspects of early development serve as prerequisites for this qualitative improvement. There are many viable candidates (e.g., shifts in referential insight, breakthroughs in joint attention, a newfound improvement in prosodic and functor-based prediction to facilitate processing, metalinguistic insight with the advent of word production, inter alia.) Properly exploring these options requires the kind of multi-task, multi-timepoint designs we recommend in the final section. Moreover, unpacking the causal inferences inherent in considering factors that may gate, correlate with, or mutually constrain each other provides fruitful fodder for modeling, experimental, and observational research.

\subsection{Symbiotic Syntheses ( $>17$ mo.)}

By the second half of year two, children are becoming word-learning aficionados. At this age, toddlers readily use others' intentions, syntax, and lexico-conceptual constraints to rapidly guide new word learning, and process utterances containing familiar words with increased efficiency (Baldwin, 1993; Tomasello, 2005; Fisher et al., 2020; McMurray et al., 2012). Considering which of these mechanisms is at play is a straw man, in part because our theories generally overstep the available data to pick between them. Moreover, there is no reason to pick a single "type" of learning account: as our framework suggests, children likely bring many learning mechanisms to the task. These symbiotic syntheses allow infants to integrate both top-down and bottom-up signals, in a way that may be superadditive.

Rather than selectively summarizing the vast literature on toddler word learning, we instead highlight a recent proposal that takes important steps towards incorporating 
recent word-learning results into a broader theory of word learning across development (Gutman et al., 2015). This work builds on the syntactic bootstrapping literature (e.g., Gleitman, 1990; Fisher et al., 2010), which proposes that young children can learn words by forming world-to-sentence mappings which rely on consistent regularities across syntactic contexts. Christophe and colleagues suggest that this process begins with a "semantic seed". Knowledge of a few content words (the seed), detection of phrasal prosody, and initial segmentation abilities in early infancy collectively reveal abstract syntactic categories and the role of function words, which the bootstrapper can then continue to build on. This proposal is supported both by computational and empirical results (Babineau et al., 2021; Gutman et al., 2015) and provides an important set of testable claims for further theory development.

Taken together, the three phases proposed here highlight both continuity and qualitative improvement in word learning over early development. Testing this proposal requires two critical next steps. The first is collecting further experimental and observational data from an expanded set of lexical classes, languages, and measures to test the robustness of the proposed phases and ages. The second is to build computational models of this and other proposals within a common framework like the one outlined above (cf. Cristia, 2020). Indeed, creating theories that factor in what infants know at different ages is vital to ensuring plausible generalization to the full challenge young word learners face.

\section{Challenges in Understanding Early Linguistic Knowl- edge}

We conclude by considering several outstanding challenges that limit a more complete understanding of how children's word knowledge develops over infancy and toddlerhood.

\subsection{Quantifying Input to the Learning Process}

A major challenge for the study of familiar word learning is that when we measure infants' word knowledge, we generally have very little information about particular infants' experiences with a given set of words. That is, we assume (ideally informed by existing relevant corpora, e.g., MacWhinney, 2000) that whatever children's experiences are, they are reasonably similar to each other. We then draw conclusions about children knowing or not knowing $\mathrm{X}$ words at $\mathrm{Y}$ age without being able to directly factor in one of the largest contributors underlying this knowledge: the input they learn from.

This limits our ability to build testable theories about how language input and knowledge are directly connected, within learners. While several seminal investigations of language development presciently measured both the language environment and children's early word knowledge within it (P. Bloom, 2002; Bates, 1979; Carpenter et al., 1998; Brown, 1973), they were often fairly limited in sampling and methodology. Recently, there has been renewed interest in this approach, paired with technological advances that make measuring receptive word knowledge and high-density, longitudinal language sampling more feasible (Casillas \& Cristia, 2019). 
Indeed, recent studies combining home environment measures with evaluations of children's early lexical knowledge have revealed connections even in the earliest stages of comprehension and production. For instance, the overall referential transparency of the situations in which words are said in infants' home environments (e.g., "here's a ball" while mother and infant look at a ball) correlates with how well those same infants understand everyday nouns at the outset of word comprehension at six months (Bergelson \& Aslin, 2017, cf Yurovsky et al., 2013 for a related point). Similarly, the spatial, temporal, and linguistic distinctiveness of the words, as heard by a single child, have been found to predict when that child begins to say those words (Roy et al., 2015).

This kind of combined approach has also highlighted that once a lexical and grammatical foundation is laid, generalization to new instances readily follows. For instance, at least by around twelve months, infants' word comprehension appears just as robust whether they engage in a looking-while-listening task that probes them with images of their own items (shoe, cat, etc.) or other tokens of such items that they have not accrued dozens to thousands of hours of experience with (Garrison et al., 2020). Relatedly, work on the determiners "a" and "the" finds that structural regularities in the input quickly permit children to find generalizations in word usage corresponding to syntactic categories (Meylan et al., 2017). Collecting dense enough data to characterize young children's everyday experiences with common words and those same children's knowledge of those words is challenging. Nevertheless, we find this to be a critical way forward for our understanding of lexical development—and language acquisition more broadly. Such an approach may find that some aspects of language input are so consistent that one group of children's experiences are an excellent proxy for another's; this remains an important empirical question.

\subsection{Reconciling Lab-based Learning with Home-based Learning}

A central challenge for novel word learning studies is the gap between the initial minutes of learning that such methods capture and the long-term exposure, learning, and refinement that occurs with "real" words that enter the vocabulary. Of course some words enter the child's vocabulary in similar ways to experimental setups (e.g., reading about wallabies in a new book is similar to some experiment's exposure phase). However, determining whether these kinds of initial abilities that lab experiments capture can scale up to everyday learning remains an important objective.

Generalizing from novel word learning experiments to everyday word learning requires caution across at least two dimensions: learning timelines, and heuristic reliance. In terms of timeline, young children are typically shown new words and their referents for mere minutes in the lab (Carey \& Bartlett, 1978), leading to learning that fades after five minutes even in preschoolers (Horst \& Samuelson, 2008). In contrast, infants' experiences with words like "dog" and "hand" (not to mention "of") are plentiful: infants amass scores of learning instances with early-learned words every day (Bergelson et al., 2018), developing lexical entries slowly over time (Swingley, 2010). The effects of this difference between lab-based exposure and home-based experience are strikingly clear in comparing the ages of children who demonstrate familiar word comprehension vs. novel word learning in the lab. While an increasing number of studies find that infants understand common nouns before 10 months, evidence of robust new word 
learning from a lab-based exposure is sparse, even in 1-year-olds who show robust comprehension for familiar words (Gonzalez-Barrero et al., 2021; Oviatt, 1980).

In terms of heuristic reliance, results based on learning from brief lab exposure appear to overemphasize children's use of heuristics like mutual exclusivity. For instance, by 17 mo. (but not earlier) infants readily use known words to scaffold new word learning in the lab (Halberda, 2003; Bergelson \& Aslin, 2017; Markman, 1990). Toddlers hearing a new word when shown a novel object and a familiar one infer that the new word applies to the new object. However, younger infants learn words without mutual exclusivity, and indeed its use varies over later development as well (Lewis et al., 2020). Moreover, mutual exclusivity is less useful for (and less used by) multilingual toddlers (Byers-Heinlein \& Werker, 2013), and surmountable for monolinguals when learning synonyms, hyponyms, and hypernyms, (e.g., toy and ball). Thus, while mutual exclusivity may aid word learning in a certain set of circumstances, it's not clear the extent to which it's actually available or useful for everyday word learning.

To us, these examples call for considering novel and familiar word knowledge within a single framework that considers the linguistic knowledge children already bring to the table in processing new words. Moreover, we encourage a front-and-center consideration of children's age and knowledge in driving what kinds of mechanisms are usable and useful for word learning.

\subsection{What Do Early Word Representations Look Like?}

Having articulated challenges and promising avenues forward in collecting and integrating data regarding early word learning, we next take up a broader question. We ask: from the perspective of young children, what are words? We further consider how a restricted range of research (i.e., concrete nouns for objects in English) limits the field's fuller characterization of early lexical knowledge.

\subsubsection{Early Words are Not Adults' Written Words}

Words separated by spaces (i.e., dictionary entries) are not what young children learn. We argue that equating children's and adults' words presupposes that 1) words exist as discrete symbolic entities in the minds of children 2) natural language consists of sequential, distinct units, which are put together to form more complex meanings (a view we dub "beads on a string") and 3) as a matter of convention, people in a community agree upon the existence of a shared inventory of word forms. While these are arguably useful simplifying assumptions for understanding adult-to-adult language usage, none should be taken for granted within children's first language learning.

Listeners impose lexical structure on children's language use Adult caregivers, and often researchers, are highly capable of ascribing distinctive, contextually-appropriate lexical interpretations to incorrect or indistinct forms produced by young children (Meylan, Foushee, et al., 2021). For example, a child may use identical sounds approximating /da/ to refer to dad and dog, while caregivers interpret them differently based on context. That is, word knowledge ascribed to children is not solely a function of the cognitive state of the child, but of both the child and the listener. Relatedly, adults may 
overactively attribute comprehension to children: just as interlocutors often assume they are calling the same ideas to mind, so too do caretakers and experimenters make assumptions about what construal of an item children are considering (e.g., Bergelson \& Swingley, 2013b, Malt \& Sloman, 2004).

Early words are not "beads on a string" An attractively simple view is that humans communicate by forming complex meanings through combining words, like threading beads on a string: each word is a bead, and the meaning can be composed from the sequence of beads. Indeed, this is the way in which sentences are composed in many writing systems. Applied to comprehension, this view suggests that children recognize the communicative intent of others by decoding the speech signal into words, and building up the meaning from the component words. However, this view has clear limits when we consider a variety of linguistic phenomena that point to a rich dependency structure within and across words. We consider the syntax-phonology interface and bi-stable sequences as examples of such phenomena.

The "beads on a string" view ignores direct dependencies between sub-word phonology and information outside of the word that are common across languages. For instance, many word forms have different realizations depending on phonological context across word boundaries (sandhi), e.g., liaison in French and "linking R" in some varieties of English (Broadbent, 1991). In other cases, a word form's realization depends on its syntactic or morphological context (e.g., consonant mutation). Children handily (if sometimes slowly) acquire these dependencies (Chevrot et al., 2013; Xu Rattanasone et al., 2018).

Similarly, English clitics like "'ll" in "he'll" and "'t" in "can't" function as syntactically independent units, yet are phonologically dependent on a "host" word. Indeed, using "contraction" to describe this presupposes a "beads on a string" analysis where the observed phonetic form is presumed to stand in for a latent multi-word sequence that undergoes phonetic reduction. But there is little reason to think forms like "can' $t$ " (or semi-auxiliaries like "gonna") are not initially standalone forms to child language learners.

Another example of dependencies across words are the bistability of single vs. multiword expressions (Sag et al., 2002; c.f. idioms, Titone \& Connine, 1999). For instance, "a lot of" (/ələdə/) functions as a determiner when used before a noun (=many), but is composed of a determiner - noun - preposition sequence. The sequence is not truly fixed, in that "a $<$ unit $>$ of" covers many possible pseudopartitive constructions ("a bunch of", "a glass of"). To assign lexical status to the component words alone (i.e., "a" "lot" and "of") is to overlook this rich locus of lexical meaning; likewise, to overlook the component parts is to overlook another.

Taken together, phenomena like these suggest that characterizing early words as "beads on a string" oversimplifies word learning. Language learning isn't recovering a disconnected inventory of form-meaning units. Rather, it is discovering the many ways components of the linguistic gestures (i.e. spoken or signed) can be combined and re-used.

So why use words as a unit in understanding child language acquisition at all? In our view, considering words as such (1) highlights the uniqueness of human commu- 
nicative symbols, and (2) more pragmatically, provides a useful intuitive shortcut to a nuanced, complex concept. To the first point, however difficult it may be to delineate what counts as a word, and what precisely qualifies as lexical knowledge, children nonetheless show a remarkable prowess in the range and richness of their communicative inventories. This stands in stark contrast to non-human primates. Whereas the average two-year-old English learning infant in the US can comprehend 230 and produce 50 words by 18 months (Frank et al., 2021), a bonobo reared in a matched, languagerich home environment could understand 70 and produce only 4 by 24 months (SavageRumbaugh et al., 1986; cf attempts at sign language learning in chimpanzees, Gardner $\&$ Gardner, 1971). This distinction is particularly intriguing in light of comparable performance between human children and non-human primates at 24 months on tasks testing physical cognition (Herrmann et al., 2010). To the second point, we can retain the notion of the word out of sheer pragmatism: researchers need a shorthand for the smallest free-standing, meaning-bearing gesture sequences, and "word" provides this, as long as its nuances and limitations are not forgotten.

\subsubsection{Early Words Are Not Necessarily Conventional}

A reasonable assumption in adult language is the conventionality of the lexicon, i.e., that different members of a speech community possess knowledge of a shared inventory of words (Clark, 1988; Sabbagh \& Henderson, 2007; Hollich et al., 2000). Conventionality supports the treatment of languages as stable entities, separate from the linguistic knowledge of individual speakers or listeners in the language. However, this conventionality too must be learned. This involves a gradual expansion from family-specific conventions to progressively broader sets of interlocutors and topics. While children appear to readily acquire strong beliefs about the breadth of linguistic conventions from infancy onward (Henderson \& Woodward, 2012; Clark, 1988; Graham et al., 2006) acquiring such beliefs is part of the learning process.

\subsubsection{Early Words Take Many Forms and Many Meanings}

A common implicit assumption is that children are learning to comprehend and to produce the lemma, or the canonical, uninflected form of a word, by linking the basic form to a single cohesive meaning (e.g., , word learning accounts in Markman, 1990; Trueswell et al., 2013). In reality, children must deal with a considerably more challenging learning task: for each word, they must learn correspondences between multiple possible word forms and multiple possible meanings.

Multiple Possible Forms In many languages, children hear many morphologically inflected variants of a word. In English, this includes a plural marker and possessive clitic for nouns, a 3rd person singular for verbs (all marked with $+/ \mathrm{s} /,+/ \mathrm{z} /$ or $+/ \mathrm{Iz} /$ ), a past tense $+/ \partial \mathrm{d} /+/ \partial \mathrm{t} /$ for verbs, and a progressive marker /my/. A common simplifying assumption among researchers studying English is that children learn to use a "basic" form such as the singular of a noun or the uninflected form of a verb, followed by the other forms. Empirical investigation reveals a more complex picture: In many cases, the inflected form is more common and potentially acquired earlier, e.g., "peas," 
"pants," and "teeth" (Sanchez et al., 2019). Moreover, morphology varies widely crosslinguistically. For instance, in some languages, the plural is the unmarked form and the singular is inflected (e.g., Welsh singulative, plant "children" vs. plentyn "a child", King, 2016) In other cases, words have a latent stem structure (e.g., trilateral roots in Semitic languages) rather than a lexicalized base form (McCarthy, 1981).

In some speech communities, children may also hear many variants of a word within and across talkers, for instance "diapey" and "diaper". These variations deviate from the lemma, but do not change the meaning. Common nouns in the speech to North American English-learning infants include frequent instances of such "wordplay", e.g., 6 forms for the word "pajamas" in one family in monthly recordings over a 12 month period (Moore \& Bergelson, 2021). Infants must learn that these variants do not change the meaning, eventually uncovering meaningful variation versus mere wordplay.

Multiple Possible Meanings Complicating matters further, many words have multiple context-specific meanings, which can be treated as discrete word senses (Miller, 1998), or gradiently related ones (Gangemi et al., 2001). These senses exhibit polysemy (related meanings for the same word form, e.g., "chicken" as an animal versus that animal's meat), or homonymy (unrelated meanings for the same word form, e.g., bank of a river versus a financial institution). Newly-collected corpora reveal that children both hear and use multiple word senses from the earliest ages (Meylan, Mankewitz, et al., 2021), consistent with experimental work showing that 3-4 year old children readily learn polysemous and homonymous words (Floyd \& Goldberg, 2021; Srinivasan et al., 2019). Dealing with polysemy and homonymy too are part of the word learner's task.

Words' multiple forms and meanings create a different (but not necessarily harder) learning task than is typically assumed. For instance, observing more inflected forms may help children to partial out the contribution of lemma and morphological marking. Similarly, inflected usages may help children identify grammatical categories (Mintz, 2003). At the same time, while "wordplay" forms have phonetic material that is not morphologically meaningful, they may instead serve as attentional highlights. Finally, the latent structure in the lexicon implicated in polysemy suggests that upon inferring a productive rule (e.g., animal and its meat), children may gain access to many additional meanings without observing them (Srinivasan et al., 2019).

\subsubsection{Beyond Words for Concrete Objects in English}

A large proportion of the literature on early word learning (our own work included) focuses on how young English-learning children learn concrete object labels, i.e., nouns. This singular focus prevents an appropriately generalizable theory of lexical development.

To state the trivially obvious, the vast majority of first language learners acquire languages other than English. From a typological perspective, English has unusual features, including a relatively large phonological inventory (compared with e.g., Japanese) and a relatively simple system of morphological inflections (compared with e.g., Turkish). Children no doubt face a particular set of challenges during word learning in each 
language (Trecca et al., 2021), though we do not yet know how much cross-linguistic variability in the early lexicon is due to the linguistic knowledge to be acquired, rather than the methods or contexts that have been studied. We particularly note the value of studying early language input and knowledge for non-Indo-European languages, whose typological divergences from the modally studied languages hold great promise for expanding our understanding of word learning (Casillas et al., 2020b,a; Cristia et al., 2019; Demuth et al., 2010; Tsuji et al., 2020; Mazuka et al., 2006).

The field's focus on early-learned nouns has multiple underlying motivations. First, words for things are overrepresented in the early vocabulary of English learners (Gentner, 1982), as well as learners of other languages (Frank et al., 2021), making them a natural focus of attention. Second, from a methodological standpoint, it is easier to measure children's understanding of such words relative to other lexical classes, particularly function words (though cf. Zangl \& Fernald, 2007; Babineau et al., 2020; Gerken $\&$ Mclntosh, 1993; Feiman et al., 2017). That is, methods like looking-while-listening readily allow a side-by-side comparison of two images depicting nouns and a simple utterance like "Where's the dog?". In contrast, testing knowledge of prepositions or even action verbs requires more complex discourse and scene-level considerations (e.g., saliency controls). Such experiments also require greater memory and attentionbased resources from participants, which can be hard to separate from the challenges of understanding the words themselves (Lidz et al., 2017; Moore \& Bergelson, in prep.).

Unfortunately, this focus on nouns sets up a situation where the kinds of theories proposed for learning concrete nouns (which can be treated as primarily a "mapping" problem between word and referent) do not readily extend to other lexical classes (which cannot). These include pronouns (whose referents change with the context of use), predicates like "all gone" and "bigger," quantifiers ("some", "all"), and other parts of speech (Rohlfing et al., 2016).

Notably, the meaning of many nouns may rely more on linguistic rather than nonlinguistic context (Brysbaert et al., 2014), raising further questions about dependencies between words. For instance, quantifiers like "all" may only be acquired once a learner has developed sufficient knowledge of nouns, i.e., things that can be quantified (cf Crain, 2017). Likewise, meanings of verbs interact with the words that populate their argument structures (cf. Gentner, 1982; Gleitman, 1990; Gutman et al., 2015).

Taken together, the literature's over-reliance on concrete nouns, and on the acquisition of English, creates theories that are self-limiting. On one hand, there does seem to be cross-linguistic consistency supporting noun dominance in the earliest lexicon (e.g. Frank et al., 2021), and particularly early learning of nouns across languages of varying language families (Bergelson \& Swingley, 2012; Kartushina \& Mayor, 2019; Parise \& Csibra, 2012). On the other, both the relative morphological barrenness of English and the methodological challenges of testing other parts of speech suggest more research is needed to understand the generalizability of lexical acquisition timelines. Resolving this concern requires concerted effort to build international, interdisciplinary collaborations collectively consider how words (and other aspects of linguistic knowledge) are learned across languages and cultures, from a broader range of perspectives (Frank et al., 2021; VanDam et al., 2016; The ManyBabies Consortium, 2020; Soderstrom et al., 2020). 


\section{Conclusion}

Over the first few years of life, children gain an enormous amount of knowledge about their language and the world around them. Word learning is an important part of this growth. It allows infants to integrate information from different levels of linguistic representation on the one hand, and social and cognitive skills on the other. As we highlight, processing and learning words are two sides of the same coin, both relying on iterative inferences across experience with utterances and contexts. But the nascent word-learner brings less-refined linguistic, social, and cognitive machinery to the table than the more experienced one, and nevertheless succeeds in building an early store of lexical items, i.e., common nouns.

As development progresses, infants learn to take better advantage of their language input. That is, initial word learning before 10 months relies on highly frequent and perceptually consistent experiences with words that have clear referents. But as learning and experience continue to accrue, infants learn more from less, using their improving parsing skills, social inferences, and memory to facilitate more efficient word learning of an ever-increasing range of words. Measures of familiar word knowledge and new word learning each help explain how this process unfolds. But integrating these approaches longitudinally alongside measures of the home environment, within children, stands to catalyze our theories and models further. In turn, understanding the earliest stages of human word learning sets the stage for a broad range of extensions. These includes application to clinical conditions where language and development are implicated, other species' communicative systems, and both cognitively plausible and implausible AI. Most broadly put, the study of early word learning provides a window to a deeper understanding of the human mind.

\section{Summary}

1. Children's language learning and processing build on one another over time, yielding a growing store of knowledge about language. This can be characterized with an iterative framework.

2. While children's linguistic knowledge changes as they see more data with age, the inventory of learning mechanisms they can use also changes. We propose three stages of learning in infancy and toddlerhood: brute force early associations (before 10mo.), a comprehension boost (12-14mo.), and symbiotic syntheses (after $17 \mathrm{mo}$ ).

3. Historically, researchers have had difficulty characterizing children's day-to-day input in the home environment cross-culturally and at scale. New dense corpora collection efforts intertwined with lab-based tests of processing and caregiver vocabulary reports can help clarify the link between input and language knowledge within and across specific children.

4. Tests of familiar word knowledge and novel word learning tap different dimensions of linguistic knowledge, but a shared reliance on utterance and non-linguistic 
context. Integrating what different approaches reveal as a function of age is likely to strengthen our understanding of the aspects of word knowledge that they reflect.

5. Understanding early word learning requires careful consideration of what children represent in their lexicons, which is not initially the conventional, spaceseparated words in the adult language. This also requires an appreciation of the task of learning correspondences between multiple possible forms and multiple possible meanings.

\section{Disclosure Statement}

The authors are not aware of any affiliations, memberships, funding, or financial holdings that might be perceived as affecting the objectivity of this review.

\section{Acknowledgements}

We thank Ruthe Foushee and members of the Bergelson Lab for helpful feedback on this work. We gratefully acknowledge support from the National Institutes of Health to SCM (1F32HD097982), and the National Science Foundation to EB (BCS-1844710).

\section{References}

Arunachalam, S., Escovar, E., Hansen, M. A., \& Waxman, S. R. (2013, April). Out of sight, but not out of mind: 21-month-olds use syntactic information to learn verbs even in the absence of a corresponding event. Language and cognitive processes, 28(4), 417-425. Retrieved 2021-04-24, from https://www.ncbi.nlm.nih.gov/ pmc/articles/PMC3805375/ doi: 10.1080/01690965.2011.641744

Babineau, M., Carvalho, A., Trueswell, J., \& Christophe, A. (2021, January). Familiar words can serve as a semantic seed for syntactic bootstrapping. Developmental Science, 24(1). Retrieved 2021-01-26, from https://onlinelibrary.wiley.com/ doi/10.1111/desc.13010 (tex.ids: babineau_familiar_nodate) doi: 10.1111/ desc. 13010

Babineau, M., Shi, R., \& Christophe, A. (2020, September). 14-month-olds exploit verbs' syntactic contexts to build expectations about novel words. Infancy, 25(5), 719-733. Retrieved 2021-01-26, from https://onlinelibrary.wiley .com/doi/abs/10.1111/infa.12354 (tex.ids: babineau_14-month-olds_2020, babineau_14-month-olds_nodate, babineau_14-month-olds_nodate-1) doi: 10.1111/ infa. 12354

Baldwin, D. A. (1993). Early referential understanding: Infants' ability to recognize referential acts for what they are. Developmental Psychology, 29(5), 832-843. Retrieved 2016-07-20, from http: / / psycnet.apa.org/journals/dev/29/5/832/ (ISBN: 0012-1649 \n1939-0599) doi: 10.1037/0012-1649.29.5.832 
Bates, E. (1979). The emergence of symbols: Cognition and communication in infancy. Academic Press.

Bates, E., \& Goodman, J. C. (1997). On The Inseparability of Grammar and the Lexicon: Evidence from Acquisition, Aphasia, and Real-Time Processing. Language and Cognitive Processes, 12(5/6), 507-584. (ISBN: 0169-0965) doi: $10.1080 / 016909697386628$

Bates, E., \& MacWhinney, B. (1989). Functionalism and the competition model. In B. MacWhinney \& E. Bates (Eds.), The Crosslinguistic Study of Sentence Processing (pp. 3-73). Cambridge University Press.

Benedict, H. (1979). Early lexical development: Comprehension and production. Journal of Child Language. Retrieved 2013-11-25, from http: / / journals . cambridge . org/production/action/cjoGetFulltext?fulltextid=1769952

Bergelson, E. (2020, September). The Comprehension Boost in Early Word Learning: Older Infants Are Better Learners. Child Development Perspectives, 14(3), 142149. Retrieved 2021-04-23, from https://onlinelibrary.wiley.com/doi/ abs/10.1111/cdep.12373 doi: 10.1111/cdep.12373

Bergelson, E., Amatuni, A., Dailey, S., Koorathota, S., \& Tor, S. (2018). Day by day, hour by hour: Naturalistic language input to infants. Developmental Science, 22(1).

Bergelson, E., \& Aslin, R. (2017). Semantic Specificity in One-Year-Olds' Word Comprehension. Language Learning and Development, 13(4), 481-501. (tex.ids: bergelson_semantic_2017-1) doi: 10.1080/15475441.2017.1324308

Bergelson, E., \& Swingley, D. (2012, February). At 6-9 months, human infants know the meanings of many common nouns. Proceedings of the National Academy of Sciences, 109(9), 3253-3258. Retrieved 2021-04-03, from http: / /www . pnas . org/ cgi/doi/10.1073/pnas.1113380109 doi: 10.1073/pnas.1113380109

Bergelson, E., \& Swingley, D. (2013a, June). The acquisition of abstract words by young infants. Cognition, 127(3), 391-397. Retrieved 2021-04-03, from https:// linkinghub.elsevier.com/retrieve/pii/S0010027713000395 doi: 10.1016/ j.cognition.2013.02.011

Bergelson, E., \& Swingley, D. (2013b). Young toddlers' word comprehension is flexible and efficient. PLoS One, 8(8), e73359. Retrieved from http:// www. pubmedcentral.nih.gov/articlerender. fcgi ?artid=3749997\&tool= pmcentrez\&rendertype=abstract doi: 10.1371/journal.pone.0073359

Bergelson, E., \& Swingley, D. (2015, October). Early Word Comprehension in Infants: Replication and Extension. Language Learning and Development, 11(4), 369380. Retrieved 2021-04-23, from http://www.tandfonline.com/doi/full/ $10.1080 / 15475441.2014 .979387$ doi: $10.1080 / 15475441.2014 .979387$

Bloom, L. (1993). The transition from infancy to language: Acquiring the power of expression. Cambridge University Press. 
Bloom, P. (2002). How children learn the meanings of words. MIT press.

Bohn, M., \& Frank, M. C. (2019). The Pervasive Role of Pragmatics in Early Language. Annual Review of Developmental Psychology, 1, 223-249.

Broadbent, J. (1991). Linking and Intrusive $\mathrm{r}$ in English. UCL Working Papers in Linguistics, 3, 22.

Brown, R. (1973). A First Language: The Early Stages. Harvard University Press.

Brysbaert, M., Warriner, A. B., \& Kuperman, V. (2014, September). Concreteness ratings for 40 thousand generally known English word lemmas. Behavior Research Methods, 46(3), 904-911. Retrieved 2021-04-23, from http://link.springer .com/10.3758/s13428-013-0403-5 doi: 10.3758/s13428-013-0403-5

Byers-Heinlein, K., \& Werker, J. F. (2013, September). Lexicon structure and the disambiguation of novel words: Evidence from bilingual infants. Cognition, 128(3), 407-416. Retrieved 2021-04-23, from https://linkinghub.elsevier.com/ retrieve/pii/S0010027713001091 doi: 10.1016/j.cognition.2013.05.010

Campbell, J. C. S. (2018). The nature of infants' early object word comprehension ( $\mathrm{PhD}$ Thesis). University of British Columbia.

Carey, S., \& Bartlett, E. (1978, January). Acquiring a Single New Word. Proceedings of the Stanford Child Language Conference, 15, 17-29.

Carpenter, M., Nagell, K., Tomasello, M., Butterworth, G., \& Moore, C. (1998). Social Cognition, Joint Attention, and Communicative Competence from 9 to 15 Months of Age. Monographs of the Society for Research in Child Development, 63(4), i. Retrieved 2021-04-23, from https://www. jstor.org/stable/1166214 ?origin=crossref doi: $10.2307 / 1166214$

Casillas, M., Brown, P., \& Levinson, S. C. (2020a, September). Early language experience in a Papuan community. Journal of Child Language, 123. Retrieved 2021-04-23, from https://www.cambridge.org/core/product/ identifier/S0305000920000549/type/journal_article doi: 10.1017/ S0305000920000549

Casillas, M., Brown, P., \& Levinson, S. C. (2020b, September). Early Language Experience in a Tseltal Mayan Village. Child Development, 91(5), 1819-1835. Retrieved 2021-04-23, from https://onlinelibrary.wiley.com/doi/10.1111/ cdev.13349 doi: 10.1111/cdev.13349

Casillas, M., \& Cristia, A. (2019). A step-by-step guide to collecting and analyzing long-format speech environment (LFSE) recordings. Collabra, 5(1).

Chater, N., Crocker, M. J., \& Pickering, M. J. (1998). The rational analysis of inquiry: The case of parsing. In Rational Models of Cognition. Oxford: Oxford University Press. 
Chevrot, J.-P., Dugua, C., Harnois-Delpiano, M., Siccardi, A., \& Spinelli, E. (2013, September). Liaison acquisition: debates, critical issues, future research. Language Sciences, 39, 83-94. Retrieved 2021-04-03, from https: / / inkinghub. el sevier .com/retrieve/pii/S0388000113000296 doi: 10.1016/j.langsci.2013.02.011

Clark, E. V. (1988, June). On the logic of contrast. Journal of Child Language, 15(2), 317-335. Retrieved 2021-04-05, from https://www.cambridge.org/ core/product/identifier/S0305000900012393/type/journal_article doi: $10.1017 / \mathrm{S} 0305000900012393$

Clark, E. V., \& Hecht, B. F. (1983, January). Comprehension, Production, and Language Acquisition. Annual Review of Psychology, 34(1), 325-349. Retrieved 2021-04-04, from http://www. annualreviews.org/doi/10.1146/annurev.ps .34 .020183 .001545 doi: 10.1146/annurev.ps.34.020183.001545

Crain, S. (2017, January). Acquisition of Quantifiers. Annual Review of Linguistics, 3(1), 219-243. Retrieved 2021-04-28, from http://www. annualreviews.org/ doi/10.1146/annurev-linguistics-011516-033930 doi: 10.1146/annurev -linguistics-011516-033930

Cristia, A. (2020, September). Language input and outcome variation as a test of theory plausibility: The case of early phonological acquisition. Developmental Review, 57, 100914. Retrieved 2021-04-27, from https://www.sciencedirect.com/ science/article/pii/S0273229720300204 doi: 10.1016/j.dr.2020.100914

Cristia, A., Dupoux, E., Gurven, M., \& Stieglitz, J. (2019, May). Child-Directed Speech Is Infrequent in a Forager-Farmer Population: A Time Allocation Study. Child Development, 90(3), 759-773. Retrieved 2021-04-23, from https:// onlinelibrary.wiley.com/doi/abs/10.1111/cdev.12974 doi: 10.1111/cdev .12974

Demuth, K., Moloi, F., \& Machobane, M. (2010). 3-Year-olds' comprehension, production, and generalization of Sesotho passives. Cognition, 115, 238-251.

Diamond, A. (1985). Development of the Ability to Use Recall to Guide Action, as Indicated by Infants' Performance on AB. Child Development, 56(4), 868-883.

Dunn, L., Dunn, L. M., Bulheller, S., \& Häcker, H. (1965). Peabody Picture Vocabulary Test. Circle Pines, MN: American Guidance Service.

Dupoux, E. (2018). Cognitive science in the era of artificial intelligence_ A roadmap for reverse-engineering the infant language-learner. Cognition, 173, 43-59.

Feiman, R., Mody, S., Sanborn, S., \& Carey, S. (2017, October). What Do You Mean, No? Toddlers' Comprehension of Logical "No" and "Not". Language Learning and Development, 13(4), 430-450. Retrieved 2021-04-23, from https: // www.tandfonline.com/doi/full/10.1080/15475441.2017.1317253 doi: 10 $.1080 / 15475441.2017 .1317253$ 
Fenson, L., Dale, P. S., Reznick, J. S., Bates, E., Thal, D. J., Pethick, S. J., ... Stiles, J. (1994). Variability in Early Communicative Development. Monographs of the Society for Research in Child Development, 59(5), i. Retrieved 2021-0425, from https://www.jstor.org/stable/1166093?origin=crossref doi: $10.2307 / 1166093$

Fernald, A., Marchman, V. A., \& Weisleder, A. (2013, March). SES differences in language processing skill and vocabulary are evident at 18 months. Developmental Science, 16(2), 234-248. Retrieved 2021-04-23, from http://doi.wiley.com/ 10.1111/desc.12019 doi: 10.1111/desc.12019

Fernald, A., Perfors, A., \& Marchman, V. A. (2006). Picking Up Speed in Understanding: Speech Processing Efficiency and Vocabulary Growth Across the 2nd Year. Developmental Psychology, 42(1), 98 - 116.

Fernald, A., Pinto, J. P., Swingley, D., Weinberg, A., \& McRoberts, G. W. (1998, May). Rapid Gains in Speed of Verbal Processing by Infants in the 2nd Year. Psychological Science, 9(3), 228-231. Retrieved 2013-11-13, from http://pss. sagepub.com/ cgi/content/long/9/3/228 (ISBN: 0-631-21744-4; 0-631-21745-2) doi: 10 $.1111 / 1467-9280.00044$

Fisher, C., Gertner, Y., Scott, R. M., \& Yuan, S. (2010, March). Syntactic bootstrapping. Wiley Interdisciplinary Reviews: Cognitive Science, 1(2), 143-149. Retrieved 2021-04-23, from https://onlinelibrary.wiley.com/doi/abs/10.1002/wcs .17 doi: $10.1002 / \mathrm{wcs} .17$

Fisher, C., \& Gleitman, L. R. (2002). Language Acquisition. In H. Pashler \& R. Gallistel (Eds.), Steven's Handbook of Experimental Psychology, Vol. 3: Learning, motivation, and emotion (3rd ed., Vol. 3, pp. 445-496). New York: Wiley.

Fisher, C., Jin, K.-s., \& Scott, R. M. (2020). The Developmental Origins of Syntactic Bootstrapping. Topics in Cognitive Science, 12(1), 48-77. Retrieved 2021-0424, from https://onlinelibrary.wiley.com/doi/abs/10.1111/tops.12447 (_eprint: https://onlinelibrary.wiley.com/doi/pdf/10.1111/tops.12447) doi: https:// doi.org/10.1111/tops. 12447

Floyd, S., \& Goldberg, A. E. (2021, January). Children make use of relationships across meanings in word learning. Journal of Experimental Psychology: Learning, Memory, and Cognition, 47(1), 29-44. Retrieved 2021-04-03, from http://doi .apa.org/getdoi.cfm?doi=10.1037/xlm0000821 doi: 10.1037/xlm0000821

Forgács, B., Parise, E., Csibra, G., Gergely, G., Jacquey, L., \& Gervain, J. (2019, March). Fourteen-month-old infants track the language comprehension of communicative partners. Developmental Science, 22(2). Retrieved 2021-04-23, from https://onlinelibrary.wiley.com/doi/abs/10.1111/desc.12751 doi: 10 $.1111 /$ desc. 12751

Frank, M. C. (2016). Chasing the Rubicon? The American Journal of Psychology, 129(1), 99-104. Retrieved 2021-04-23, from https://www.jstor.org/stable/ 
10.5406/amerjpsyc.129.1.0099 (Publisher: University of Illinois Press) doi: 10.5406/amerjpsyc.129.1.0099

Frank, M. C., Braginsky, M., Yurovsky, D., \& Marchman, V. A. (2021). Variability and Consistency in Early Language Learning: The Wordbank Project. Cambridge, MA: MIT Press.

Frank, M. C., Goodman, N. D., \& Tenenbaum, J. B. (2009). Using Speakers' Referential Intentions to Model Early Cross-Situational Word Learning. Psychological Science, 20(5), 578-585.

Frank, M. C., Vul, E., \& Johnson, S. P. (2009, February). Development of infants' attention to faces during the first year. Cognition, 110(2), 160-70. Retrieved 2014-01-22, from http: //www.sciencedirect.com/science/article/ pii/S0010027708002606 doi: 10.1016/j.cognition.2008.11.010

Friend, M., Schmitt, S. A., \& Simpson, A. M. (2012, January). Evaluating the predictive validity of the computerized comprehension task: comprehension predicts production. Developmental Psychology, 48(1), 136-148. (tex.ids= friend_evaluating_2012-1) doi: 10.1037/a0025511

Gangemi, A., Guarino, N., \& Oltramari, A. (2001). Conceptual analysis of lexical taxonomies: The case of WordNet top-level. In Proceedings of the international conference on Formal Ontology in Information Systems-Volume 2001 (pp. 285-296).

Gardner, B. T., \& Gardner, R. A. (1971). Two-way communication with an infant chimpanzee. In Behavior of nonhuman primates (Vol. 4, pp. 117-184). Elsevier.

Garrison, H., Baudet, G., Breitfeld, E., Aberman, A., \& Bergelson, E. (2020, July). Familiarity plays a small role in noun comprehension at 12-18 months. Infancy, 25(4), 458-477. Retrieved 2021-04-23, from https://onlinelibrary.wiley.com/ doi/abs/10.1111/infa.12333 doi: 10.1111/infa.12333

Gentner, D. (1982). Why Nouns are Learned Before Verbs : Linguistic Relativity versus Natural Partitioning. In Lanugage, thought, and culture (Vol. 2, pp. 301 334). Hillsdale, NJ: Lawrence Erlbaum.

Gerken, L., \& Mclntosh, B. J. (1993). Interplay of Function Morphemes and Prosody in Early Language. Developmental Psychology, 29(3), 448-457.

Gibson, E., Bergen, L., \& Piantadosi, S. (2013). Rational integration of noisy evidence and prior semantic expectations in sentence interpretation. Proc. Natl. Acad. Sci. U.S.A., 110(20), 8051-8056.

Gleitman, L. R. (1990). The Structural Sources of Verb Meanings. Language Acquisition, $1(1), 54$.

Goldwater, S., Griffiths, T. L., \& Johnson, M. (2009, July). A Bayesian framework for word segmentation: Exploring the effects of context. Cognition, 112(1), 21-54. Retrieved 2021-04-23, from https: / / inkinghub.elsevier.com/retrieve/pii/ S0010027709000675 doi: 10.1016/j.cognition.2009.03.008 
Golinkoff, R. M., Ma, W., Song, L., \& Hirsh-Pasek, K. (2013, May). Twenty-Five Years Using the Intermodal Preferential Looking Paradigm to Study Language Acquisition: What Have We Learned? Perspectives on psychological science : a journal of the Association for Psychological Science, 8(3), 316-339. Retrieved from http://pps.sagepub.com/lookup/doi/10.1177/1745691613484936 (ISBN: 9780874216561) doi: 10.1177/1745691613484936

Gonzalez-Barrero, A. M., Ben, R. D., Killam, H., \& Byers-Heinlein, K. (2021, April). Word learning in the lab is hard! Data from 14-month-old monolingual and bilingual infants (Tech. Rep.). PsyArXiv. Retrieved 2021-04-20, from https://psyarxiv .com/5dvx8/ (type: article) doi: 10.31234/osf.io/5dvx8

Graham, S. A., Stock, H., \& Henderson, A. M. E. (2006, May). Nineteen-Month-Olds' Understanding of the Conventionality of Object Labels Versus Desires. Infancy, 9(3), 341-350. Retrieved 2021-04-05, from http://doi.wiley.com/10.1207/ s15327078in0903_5 doi: 10.1207/s15327078in0903_5

Grice, H. (1975). Logic and Conversation. In Speech acts. New York: Elsevier. (OCLC: 256078909)

Griffiths, T. L., Chater, N., Kemp, C., Perfors, A., \& Tenenbaum, J. B. (2010, August). Probabilistic models of cognition: exploring representations and inductive biases. Trends in Cognitive Sciences, 14(8), 357-364. Retrieved 2021-04-26, from https://linkinghub.elsevier.com/retrieve/pii/ S1364661310001129 doi: 10.1016/j.tics.2010.05.004

Gutman, A., Dautriche, I., Crabbé, B., \& Christophe, A. (2015, July). Bootstrapping the Syntactic Bootstrapper: Probabilistic Labeling of Prosodic Phrases. Language Acquisition, 22(3), 285-309. Retrieved 2021-04-10, from https:// doi.org/10.1080/10489223.2014.971956 (Publisher: Routledge _eprint: https://doi.org/10.1080/10489223.2014.971956) doi: 10.1080/10489223.2014 .971956

Halberda, J. (2003). The development of a word-learning strategy. Cognition, 87, B23-B34. (ISBN: 1161738479) doi: 10.1016/S0010-0277(02)00186-5

Henderson, A. M. E., \& Woodward, A. L. (2012, September). Ninemonth-old infants generalize object labels, but not object preferences across individuals. Developmental Science, 15(5), 641-652. Retrieved 2013-1108, from http://www.pubmedcentral.nih.gov/articlerender.fcgi?artid=

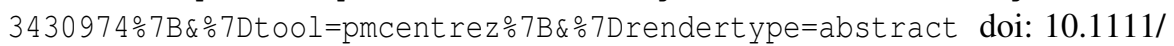
j.1467-7687.2012.01157.x

Herrmann, E., Hare, B., Call, J., \& Tomasello, M. (2010, August). Differences in the Cognitive Skills of Bonobos and Chimpanzees. PLoS ONE, 5(8), e12438. Retrieved 2021-04-12, from https://dx.plos.org/10.1371/journal .pone.0012438 doi: 10.1371/journal.pone.0012438 
Hill, F., Tieleman, O., von Glehn, T., Wong, N., Merzic, H., \& Clark, S. (2020, October). Grounded Language Learning Fast and Slow. arXiv:2009.01719 [cs]. Retrieved 2021-04-25, from http://arxiv.org/abs/2009.01719 (arXiv: 2009.01719)

Hollich, G., Hirsh-Pasek, K., \& Golinkoff, R. M. (2000, June). What Does it Take to Learn a Word? Monographs of the Society for Research in Child Development, 65(3), 1-16. Retrieved 2021-04-23, from https://onlinelibrary.wiley.com/ doi/abs/10.1111/1540-5834.00091 doi: 10.1111/1540-5834.00091

Hollich, G., Jusczyk, P. W., \& Brent, M. R. (2001). How Infants Use the Words They Know to Learn New Words. In Proceedings of the 25th Annual Boston University Conference on Language Development (p. 12).

Horst, J. S. (2016). The Novel Object and Unusual Name (NOUN) Database: A collection of novel images for use in experimental research. , 17.

Horst, J. S., \& Samuelson, L. K. (2008, March). Fast Mapping but Poor Retention by 24-Month-Old Infants. Infancy, 13(2), 128-157. Retrieved 2021-0423, from http://doi.wiley.com/10.1080/15250000701795598 doi: 10.1080/ 15250000701795598

Johnson, E. K. (2016). Constructing a Proto-Lexicon: An Integrative View of Infant Language Development. Annual Review of Linguistics, 2(1), 923255415. Retrieved from http://www.annualreviews.org/doi/10.1146/ annurev-linguistics-011415-040616 doi: 10.1146/annurev-linguistics $-011415-040616$

Kadlaskar, G., Waxman, S., \& Seidl, A. (2020, December). Does Human Touch Facilitate Object Categorization in 6-to-9-Month-Old Infants? Brain Sciences, 10(12), 940. Retrieved 2021-04-14, from https://www.mdpi.com/2076-3425/10/12/ 940 (Number: 12 Publisher: Multidisciplinary Digital Publishing Institute) doi: 10.3390/brainsci10120940

Kartushina, N., \& Mayor, J. (2019, September). Word knowledge in six- to ninemonth-old Norwegian infants? Not without additional frequency cues. Royal Society Open Science, 6(9), 180711. Retrieved 2021-04-23, from https:// royalsocietypublishing.org/doi/10.1098/rsos.180711 doi: 10.1098/rsos .180711

Katz, N., Baker, E., \& Macnamara, J. (1974). What's in a Name? A Study of How Children Learn Common and Proper Names. Child Development, 45(2), 469 - 473.

Kidd, E., \& Donnelly, S. (2020). Individual Differences in First Language Acquisition. Annual Review of Linguistics, 6(1), 319-340. Retrieved 2021-03-10, from https://doi.org/10.1146/annurev-linguistics-011619-030326 (_eprint: https://doi.org/10.1146/annurev-linguistics-011619-030326) doi: 10.1146/annurev -linguistics-011619-030326 
King, G. (2016). Modern Welsh: a comprehensive grammar (Third Edition ed.). London ; New York: Routledge.

Levy, R. (2008). A noisy-channel model of rational human sentence comprehension under uncertain input. In Proceedings of the Conference on Empirical Methods in Natural Language Processing - EMNLP'08 (p. 234). Honolulu, Hawaii: Association for Computational Linguistics. Retrieved 2021-04-23, from http://portal.acm.org/citation.cfm?doid=1613715.1613749 doi: $10.3115 / 1613715.1613749$

Lewis, M., Cristiano, V., Lake, B. M., Kwan, T., \& Frank, M. C. (2020, May). The role of developmental change and linguistic experience in the mutual exclusivity effect. Cognition, 198, 104191. Retrieved 2020-11-15, from http:// www.sciencedirect.com/science/article/pii/s001002772030010X doi: 10 .1016/j.cognition.2020.104191

Lidz, J., White, A. S., \& Baier, R. (2017, September). The role of incremental parsing in syntactically conditioned word learning. Cognitive Psychology, 97, 6278. Retrieved 2021-04-26, from https://www.sciencedirect.com/science/ article/pii/S0010028516302742 doi: 10.1016/j.cogpsych.2017.06.002

Lieder, F., \& Griffiths, T. L. (2019). Resource-rational analysis: Understanding human cognition as the optimal use of limited computational resources. Behavioral and Brain Sciences, 43(e1), 1-60. doi: doi:10.1017/S0140525X1900061X

MacWhinney, B. (2000). The CHILDES Project: Tools for analyzing talk. transcription format and programs. Psychology Press.

Magnuson, J. S. (2017). Mapping spoken words to meaning. In Speech Perception and Spoken Word Recognition. New York: Routledge.

Malt, B. C., \& Sloman, S. A. (2004). Conversation and convention: Enduring influences on name choice for common objects. Memory and Cognition, 32(8), 13461354.

Markman, E. M. (1990). Constraints Children Place on Word Meanings. Cognitive Science, 14, 57-77.

Marr, D. (1982). Vision: a computational investigation into the human representation and processing of visual information. Cambridge, Mass: MIT Press. (OCLC: ocn472791457)

Mazuka, R., Igarashi, Y., \& Nishikawa, K. (2006, July). Input for Learning Japanese : RIKEN Japanese Mother-Infant Conversation Corpus. IEICE technical report, 106(165), 11-15. Retrieved 2021-04-26, from https://ci.nii.ac.jp/naid/ 110004809988/ (Publisher: The Institute of Electronics, Information and Communication Engineers)

McCarthy, J. J. (1981). A prosodic theory of nonconcatenative morphology. Linguistic Inquiry, 26. 
McMurray, B., Horst, J. S., \& Samuelson, L. K. (2012, October). Word learning emerges from the interaction of online referent selection and slow associative learning. Psychological review, 119(4), 831-877. Retrieved 2013-1112, from http://www.pubmedcentral.nih.gov/articlerender.fcgi?artid= $3632668 \% 7 \mathrm{~B} \& \%$ Dtool=pmcentre $\%$ 7B\& $\%$ Drendertype=abstract doi: $10.1037 /$ a0029872

Meylan, S. C., Foushee, R., Bergelson, E., \& Levy, R. P. (2021). Child-directed Listening: How Caregiver Inference Enables Children's Early Verbal Communication. (_eprint: 2102.03462)

Meylan, S. C., Frank, M. C., Roy, B. C., \& Levy, R. (2017). The Emergence of an Abstract Grammatical Category in Children's Early Speech. Psychological Science, 28(2), 181-192.

Meylan, S. C., Mankewitz, J., Floyd, S., Rabagliati, H., \& Srinivasan, M. (2021). Quantifying Lexical Ambiguity in Speech To and From English-Learning Children. In Proceedings of the 43rd Annual Meeting of the Cognitive Science Society (pp. 252-364). Boston, MA: Cascadilla Press.

Meylan, S. C., Nair, S., \& Griffiths, T. L. (2021, May). Evaluating models of robust word recognition with serial reproduction. Cognition, 210, 104553. Retrieved 2021-04-23, from https: / / inkinghub.elsevier.com/retrieve/pii/ S0010027720303723 doi: 10.1016/j.cognition.2020.104553

Miller, G. A. (1998). WordNet: An electronic lexical database. MIT press.

Mintz, T. H. (2003, November). Frequent frames as a cue for grammatical categories in child directed speech. Cognition, 90(1), 91-117. Retrieved 2021-04-07, from https: / / linkinghub.elsevier.com/retrieve/pii/ S0010027703001409 doi: 10.1016/S0010-0277(03)00140-9

Mollica, F., \& Piantadosi, S. T. (2017, September). How Data Drive Early Word Learning: A Cross-Linguistic Waiting Time Analysis. Open Mind, 1(2), 6777. Retrieved 2021-04-23, from https: //direct.mit.edu/opmi/article/1/2/ 67-77/2940 doi: 10.1162/OPMI_a_00006

Moon, C., Lagercrantz, H., \& Kuhl, P. K. (2013). Language experienced in utero affects vowel perception after birth: a two-country study. Acta Paediatrica, 102(2), 156-160. Retrieved 2021-04-20, from https://onlinelibrary.wiley.com/doi/abs/10.1111/apa.12098 (_eprint: https://onlinelibrary.wiley.com/doi/pdf/10.1111/apa.12098) doi: https://doi.org/10 $.1111 /$ apa.12098

Moore, C., \& Bergelson, E. (2021). Wordplay: Another Confounding Source of Variability in Speech to Children (Tech. Rep.).

Moore, C., \& Bergelson, E. (in prep.). Examining the roles of regularity and lexical class in 18-26-month-olds' representations of how words sound. 
Naigles, L. (1990, June). Children use syntax to learn verb meanings. Journal of Child Language, 17(2), 357-374. Retrieved 2021-04-24, from https:// www. cambridge.org/core/product/identifier/S0305000900013817/type/ journal_article doi: 10.1017/S0305000900013817

Naigles, L. R. (2021, February). It Takes All Kinds (of Information) to Learn a Language: Investigating the Language Comprehension of Typical Children and Children With Autism. Current Directions in Psychological Science, 30(1), 1118. Retrieved 2021-04-23, from http://journals . sagepub.com/doi/10.1177/ 0963721420969404 doi: 10.1177/0963721420969404

Omaki, A., \& Lidz, J. (2015, April). Linking Parser Development to Acquisition of Syntactic Knowledge. Language Acquisition, 22(2), 158-192. Retrieved 2021-04-24, from https://doi.org/10.1080/10489223.2014.943903 (Publisher: Routledge _eprint: https://doi.org/10.1080/10489223.2014.943903) doi: 10.1080/10489223.2014.943903

Oviatt, S. L. (1980). The Emerging Ability to Comprehend Language: An Experimental Approach. Child Development, 51(1), 97-106.

Parise, E., \& Csibra, G. (2012, July). Electrophysiological Evidence for the Understanding of Maternal Speech by 9-Month-Old Infants. Psychological Science, 23(7), 728-733. Retrieved 2021-04-23, from http://journals.sagepub.com/ doi/10.1177/0956797612438734 doi: 10.1177/0956797612438734

Perfors, A., Tenenbaum, J. B., \& Regier, T. (2011, March). The learnability of abstract syntactic principles. Cognition, 118(3), 306-338. Retrieved 2021-04-23, from https://linkinghub.elsevier.com/retrieve/pii/ S0010027710002593 doi: 10.1016/j.cognition.2010.11.001

Pilley, J. W. (2013, November). Border collie comprehends sentences containing a prepositional object, verb, and direct object. Learning and Motivation, 44(4), 229-240. Retrieved 2021-04-23, from https://linkinghub.elsevier.com/ retrieve/pii/S002396901300026X doi: 10.1016/j.lmot.2013.02.003

Pinker, S. (1979). Formal models of language learning. Cognition, 7, 217-283.

Plunkett, K. (1997, July). Theories of early language acquisition. Trends in Cognitive Sciences, 1(4), 146-153. Retrieved 2021-04-23, from https:// linkinghub.elsevier.com/retrieve/pii/S1364661397010395 doi: 10.1016/ S1364-6613(97)01039-5

Polka, L., \& Werker, J. F. (1994). Developmental Changes in Perception of Nonnative Vowel Contrasts. Journal of Experimental Psychology: Perception and Performance, 20(2), 421-435.

Regier, T., \& Gahl, S. (2004, September). Learning the unlearnable: the role of missing evidence. Cognition, 93(2), 147-155. Retrieved 2021-04-23, from https:// linkinghub.elsevier.com/retrieve/pii/s0010027704000587 doi: 10.1016/ j.cognition.2003.12.003 
Rohlfing, K. J., Wrede, B., Vollmer, A.-L., \& Oudeyer, P.-Y. (2016, April). An Alternative to Mapping a Word onto a Concept in Language Acquisition: Pragmatic Frames. Frontiers in Psychology, 7. Retrieved 2021-04-07, from http:// journal .frontiersin.org/Article/10.3389/fpsyg.2016.00470/abstract doi: 10 .3389/fpsyg.2016.00470

Roy, B. C., Frank, M. C., DeCamp, P., Miller, M., \& Roy, D. (2015). Predicting the birth of a spoken word. Proc. Natl. Acad. Sci. U.S.A., 112(41), 12663-1266.

Sabbagh, M. A., \& Henderson, A. M. E. (2007). How an appreciation of conventionality shapes early word learning. New Directions for Child and Adolescent Development, 2007(115), 25-37. Retrieved 2021-04-05, from http://doi.wiley.com/ $10.1002 / \mathrm{cd} .180$ doi: $10.1002 / \mathrm{cd} .180$

Sag, I. A., Baldwin, T., Bond, F., Copestake, A., \& Flickinger, D. (2002). Multiword Expressions: A Pain in the Neck for NLP. In G. Goos, J. Hartmanis, J. van Leeuwen, \& A. Gelbukh (Eds.), Computational Linguistics and Intelligent Text Processing (Vol. 2276, pp. 1-15). Berlin, Heidelberg: Springer Berlin Heidelberg. Retrieved 2021-04-05, from http://link.springer.com/10.1007/ 3-540-45715-1_1 (Series Title: Lecture Notes in Computer Science) doi: 10.1007/3-540-45715-1_1

Salverda, A. P., \& Tanenhaus, M. K. (2017). The visual world paradigm. In A. de Groot M.B. \& P. Hagoort (Eds.), Research methods in psycholinguistics and the neurobiology of language: A practical guide (Vol. 9, pp. 89-110). Hoboken, NJ: Wiley Blackwell.

Sanchez, A., Meylan, S. C., Braginsky, M., MacDonald, K. E., Yurovsky, D., \& Frank, M. C. (2019, August). childes-db: A flexible and reproducible interface to the child language data exchange system. Behavior Research Methods, 51(4), 1928-1941. Retrieved 2021-04-28, from http://link. springer.com/10.3758/s13428-018 -1176-7 doi: 10.3758/s13428-018-1176-7

Savage-Rumbaugh, S., McDonald, K., Sevcik, R. A., Hopkins, W. D., \& Rubert, E. (1986). Spontaneous symbol acquisition and communicative use by pygmy chimpanzees (Pan paniscus). Journal of Experimental Psychology: General, 115(3), 211. (Publisher: American Psychological Association)

Shannon, C. (1948). A mathematical theory of communication. The Bell System Technical Journal, 27(July 1928), 379-423.

Shi, R. (2014, March). Functional Morphemes and Early Language Acquisition. Child Development Perspectives, 8(1), 6-11. Retrieved 2021-04-03, from http://doi .wiley.com/10.1111/cdep.12052 doi: 10.1111/cdep.12052

Smith, L. B. (2000). Learning How to Learn Words: An Associative Crane. In Becoming a Word Learner: A Debate on Lexical Acquisition. Oxford Scholarship Online. 
Smith, L. B., \& Yu, C. (2008, March). Infants rapidly learn word-referent mappings via cross-situational statistics. Cognition, 106(3), 1558-1568. Retrieved 2013-1108, from http://www.pubmedcentral.nih.gov/articlerender.fcgi?artid=

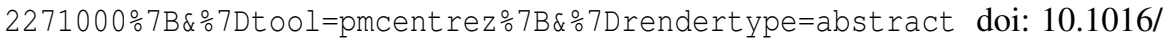
j.cognition.2007.06.010

Snedeker, J., Geren, J., \& Shafto, C. L. (2007, January). Starting Over: International Adoption as a Natural Experiment in Language Development. Psychological Science, 18(1), 79-87. Retrieved 2021-04-23, from http://journals .sagepub.com/doi/10.1111/j.1467-9280.2007.01852.x doi: 10.1111/j.1467 $-9280.2007 .01852 . x$

Soderstrom, M., Casillas, M., Bergelson, E., Rosemberg, C., Alam, F., Warlaumont, A. S., \& Bunce, J. (2020, September). Developing A Cross-Cultural Annotation System and MetaCorpus for Studying Infants' Real World Language Experience (Tech. Rep.). PsyArXiv. Retrieved 2021-04-23, from https://psyarxiv.com/bf63y/ (type: article) doi: 10.31234/osf.io/bf63y

Srinivasan, M., Berner, C., \& Rabagliati, H. (2019, May). Children use polysemy to structure new word meanings. Journal of Experimental Psychology: General, 148(5), 926-942. Retrieved 2021-04-03, from http://doi.apa.org/getdoi.cfm ?doi=10.1037/ xge0000454 doi: 10.1037/xge0000454

Swingley, D. (2009, December). Contributions of infant word learning to language development. Philosophical transactions of the Royal Society of London. Series B, Biological sciences, 364(1536), 3617-3632. Retrieved 2013-11-13, from http://www.ncbi.nlm.nih.gov/entrez/ query. fcgi?tmpl=NoSidebarfile $\& \mathrm{db}=\mathrm{PubMed} \& \mathrm{cmd}=$ Retrieve\&list_uids $=$ 19933136\&dopt=Abstract $\% 5 \mathrm{Cnhttp}: / /$ www.ncbi.nlm.nih.gov/sites/ entrez? $\mathrm{cmd}=$ Search\&db=PubMed\&term=Swingley20d (ISBN: 0962-8436) doi: 10.1098/rstb.2009.0107

Swingley, D. (2010, June). Fast Mapping and Slow Mapping in Children's Word Learning. Language Learning and Development, 6(3), 179-183. Retrieved 202104-23, from http://www.tandfonline.com/doi/abs/10.1080/15475441.2010 .484412 doi: $10.1080 / 15475441.2010 .484412$

Syrett, K., Arunachalam, S., \& Waxman, S. R. (2014, July). Slowly but Surely: Adverbs Support Verb Learning in 2-Year-Olds. Language learning and development : the official journal of the Society for Language Development, 10(3), 263-278. Retrieved 2021-04-24, from https://www.ncbi.nlm.nih.gov/pmc/articles/ PMC4134913/ doi: 10.1080/15475441.2013.840493

The ManyBabies Consortium. (2020). Quantifying Sources of Variability in Infancy Research Using the Infant-Directed-Speech Preference. Advances in Methods and Practices in Psychological Science, 3(1), 24-52. 
Tincoff, R., \& Jusczyk, P. W. (1999, March). Some Beginnings of Word Comprehension in 6-Month-Olds. Psychological Science, 10(2), 172-175. Retrieved 201311-12, from http://pss.sagepub.com/cgi/content/long/10/2/172 doi: 10.1111/1467-9280.00127

Tincoff, R., \& Jusczyk, P. W. (2012, July). Six-Month-Olds Comprehend Words That Refer to Parts of the Body: SIX-MONTH-OLDS COMPREHEND WORDS. Infancy, 17(4), 432-444. Retrieved 2021-04-23, from http://doi.wiley.com/ $10.1111 / j .1532-7078.2011 .00084 . x$ doi: 10.1111/j.1532-7078.2011.00084.x

Titone, D. A., \& Connine, C. M. (1999, November). On the compositional and noncompositional nature of idiomatic expressions. Journal of Pragmatics, 31(12), 1655-1674. Retrieved 2021-04-03, from https://linkinghub.elsevier.com/ retrieve/pii/S0378216699000089 doi: 10.1016/S0378-2166(99)00008-9

Tomasello, M. (2005). Constructing a language: a usage-based theory of language acquisition (1. Harvard Univ. Press paperback ed ed.). Cambridge, Mass.: Harvard Univ. Press. (OCLC: 254708552)

Tomasello, M., \& Stahl, D. (2004, February). Sampling children's spontaneous speech: how much is enough? Journal of Child Language, 31(1), 101-121. Retrieved 2021-04-23, from https://www.cambridge.org/core/ product/identifier/S0305000903005944/type/journal_article doi: 10 $.1017 / \mathrm{S} 0305000903005944$

Trecca, F., Tylén, K., Højen, A., \& Christiansen, M. H. (2021). Danish as a Window Onto Language Processing and Learning. Language Learning, $n / a(\mathrm{n} / \mathrm{a})$. Retrieved 2021-04-27, from https://onlinelibrary.wiley.com/doi/abs/10.1111/ lang.12450 (_eprint: https://onlinelibrary.wiley.com/doi/pdf/10.1111/lang.12450) doi: https://doi.org/10.1111/lang.12450

Trueswell, J. C., Medina, T. N., Hafri, A., \& Gleitman, L. R. (2013, February). Propose but verify: Fast mapping meets cross-situational word learning. Cognitive Psychology, 66(1), 126-156. Retrieved 2021-04-03, from https:// linkinghub.elsevier.com/retrieve/pii/S0010028512000795 doi: 10.1016/ j.cogpsych.2012.10.001

Tsuji, S., Jincho, N., Mazuka, R., \& Cristia, A. (2020, March). Communicative cues in the absence of a human interaction partner enhance 12-month-old infants' word learning. Journal of Experimental Child Psychology, 191, 104740. Retrieved 2020-11-15, from http: / / www. sciencedirect.com/science/article/ pii/S0022096519301961 (tex.ids= tsuji_communicative_2020-1) doi: 10.1016/ j.jecp.2019.104740

VanDam, M., Bergelson, E., Soderstrom, M., \& MacWhinney, B. (2016). HomeBank: An Online Repository of Daylong Child-Centered Audio Recordings. Semin Speech Lang, 37, 128-142. 
Waxman, S. R., Lidz, J. L., Braun, I. E., \& Lavin, T. (2009). Twenty four-monthold infants' interpretations of novel verbs and nouns in dynamic scenes. Cognitive Psychology, 29.

Weisleder, A., \& Fernald, A. (2013, November). Talking to Children Matters: Early Language Experience Strengthens Processing and Builds Vocabulary. Psychological Science, 24(11), 2143-2152. Retrieved 2021-04-25, from http://journals.sagepub.com/doi/10.1177/0956797613488145 doi: 10 $.1177 / 0956797613488145$

Woodward, A. L., Markman, E. M., \& Fitzsimmons, C. M. (1994). Rapid Word Learning in 13- and 18-Month-Olds. Developmental Psychology, 30(4), 533-566.

Woodward, A. L., Sommerville, J. A., Gerson, S., Henderson, A. M., \& Buresh, J. (2009). Chapter 6 The Emergence of Intention Attribution in Infancy. In Psychology of Learning and Motivation (Vol. 51, pp. 187-222). Elsevier. Retrieved 2021-04-27, from https://linkinghub.elsevier.com/retrieve/pii/ S0079742109510067 doi: 10.1016/S0079-7421(09)51006-7

Xu Rattanasone, N., Tang, P., Yuen, I., Gao, L., \& Demuth, K. (2018, May). FiveYear-olds' Acoustic Realization of Mandarin Tone Sandhi and Lexical Tones in Context Are Not Yet Fully Adult-Like. Frontiers in Psychology, 9, 817. Retrieved 2021-04-03, from https://www.frontiersin.org/article/10.3389/ fpsyg.2018.00817/full doi: 10.3389/fpsyg.2018.00817

Yang, C. (2013, April). Ontogeny and phylogeny of language. Proceedings of the National Academy of Sciences, 110(16), 6324-6327. Retrieved 2021-04-07, from http://www.pnas.org/cgi/doi/10.1073/pnas.1216803110 doi: 10.1073/ pnas.1216803110

Yurovsky, D., Wade, A., \& Frank, M. C. (2013). Online Processing of Speech and Social Information in Early Word Learning. In Proceedings of the 35th Annual Conference of the Cognitive Science Society.

Zangl, R., \& Fernald, A. (2007, June). Increasing Flexibility in Children's Online Processing of Grammatical and Nonce Determiners in Fluent Speech. Language Learning and Development, 3(3), 199-231. Retrieved 2021-04-04, from http:// www.tandfonline.com/doi/abs/10.1080/15475440701360564 doi: 10.1080/ 15475440701360564 